Gut, 1984, 25, 1029-1033

Liver and biliary

\title{
Gall stones and mortality: a study of all gall stone related deaths in a single health district
}

\author{
P J GODREY, T BATES, M HARRISON, M B KING, AND N R PADLEY \\ From the William Harvey Hospital, Ashford, Kent
}

SUMmaRY In a prospective study of gall stone related deaths in a single Health District, the biliary tract was examined at necropsy in 1701 cases and 8078 death certificates were searched. Gall stones were identified as the cause of death in only 21 cases $(0.26 \%)$ but in 291 subjects found to have gall stones or cholecystectomy at necropsy, the mortality was $3.4 \%$. The necropsy prevalence of gall stones in the adult population was $17.1 \%$ but nine out of 10 subjects with gall stones had not had a cholecystectomy and women were three times more likely to have had their gall stones removed than men. There were five postoperative deaths (mean age 60 years) with an operative mortality for cholecystectomy in the district of $1.2 \%$. Death due to unoperated gall stones was identified in 16 subjects, most of whom were very elderly women (mean age 81) but carcinoma of the gall bladder was only found in one woman of 90 with gall stones. The prevalence of gall stones rose with age in both sexes but the cholecystectomy rate per head of population at-risk declined sharply in the seventh decade in women and the eighth decade in men. There are a large number of people with unoperated gall stones in the population but gall stone related deaths are very uncommon. The cholecystectomy rate in Britain, however, seems to be rising and it is suggested that if this trend continues there may be an increased number of deaths.

Cholecystectomy is one of the most frequently performed major operations and the operative mortality for elective surgery is generally felt to be acceptable. In patients under the age of 50 years this may be as low as $0.1 \%$ but when complications arise in the elderly the mortality rises to about $10 \% .^{1}$ Glenn has therefore argued for the removal of all gall stones in the young and otherwise fit patient to avoid the high mortality of complications in the elderly.

The prevailing view of the natural history of unoperated gall stones largely rests on two earlier studies. Wenckert and Roberton ${ }^{2}$ studied a series of patients with symptomatic gall stones in whom operation had been delayed for more than one year and compared them with those who had had an early elective operation. In the delayed group, half developed further symptoms and a third had severe complications or required operation, especially the elderly; but despite this the actual mortality rate of $1.7 \%$ was little different from the overall group

Address for correspondence: $\mathrm{Mr} \mathrm{T}$ Bates, FRCS. The William Harvey Hospital, Kennington Road, Willesborough, Kent TN24 0LZ

Received for publication 13 January 1984
$(1 \cdot 6 \%)$. It has also been suggested that $50 \%$ of silent gall stones found coincidentally at operation become symptomatic sooner or later. ${ }^{3}$ Early studies such as this have considered dyspepsia to be gall stone related, however, whereas Gracie and Ransohoff ${ }^{4}$ have recently shown that, at least in men, development of biliary pain or complications occur in only $18 \%$ of cases. Furthermore, a conservative attitude was found to be entirely safe.

There are numerous reports of the operative mortality of cholecystectomy which range between $1.1 \%$ and $2.9 \%$ but there is no sign of this level getting lower with the advent of modern technology. It has been shown, however, that the cholecystectomy rate in this country is rising. ${ }^{6-10}$ Bateson and Bouchier ${ }^{11}$ in a retrospective necropsy study found that gall stone related deaths accounted for $1.1 \%$ of all deaths and that $57 \%$ of these followed cholecystectomy. Few studies have examined the overall mortality of gall stones and it was therefore decided to make a prospective examination of all deaths within a single health district. The rising cholecystectomy rate in another health district $^{7}$ was further investigated after an interval of 10 years. 


\section{Methods}

\section{SUBJECTS}

A prospective necropsy study of the biliary tract on all subjects over the age of 19 years who had been resident in south east Kent was undertaken by three pathologists between July 1978 and November 1980 , inclusively. Subjects who had had a cholecystectomy were considered to have had gall stones and the bile ducts were examined in all cases of gall stone disease. In parallel to this study, all death certificates issued to adults over the same period were searched for the principal and subsidiary causes of death. The number of cholecystectomies carried out during this period was determined by study of the operating theatre books of all NHS and private hospitals in the district. The age and sex of patients undergoing cholecystectomy were compared with the estimated number of men and women in the population for each decade.

In a separate part of the study the cholecystectomy rate in Luton for 1981 was estimated using the same method as that for 1961 and $1971 .^{7}$

The term gall stone related death was applied to all subjects who had died in hospital after a cholecystectomy and to those subjects having necropsy in which the pathologist indicated that gall stones were contributory to the death. In those subjects who did not have necropsy, death was recorded as being gall stone related if this was indicated on the death certificate or if a diagnosis of pancreatitis was made in women or in men over 50 .

\section{Results}

Over the two and a half years, 8078 death certificates were issued for residents of the southeast Kent Health District who were over the age of 19. Necropsies were carried out on $1722(21 \%)$ of these but 21 subjects were excluded because the age or address was not recorded, the examination of the biliary tree was not recorded or the cause of death made the examination impossible.

Of the 1701 cases studied, the biliary tract was examined at necropsy in 992 men and 709 women. Gall stones or a previous cholecystectomy were found in 123 men $(12.4 \%)$ and 168 women $(23.7 \%)$ with an overall prevalence of $17 \cdot 1 \%$. The prevalence of gall stones increased with age (Fig. 1) although the numbers in the third and fourth decades were small as were the number of men in the ninth decade. The necropsy prevalence of cholecystectomy in those with gall stones was $10.7 \%$ but in men this was only $4.8 \%$ compared with $14.9 \%$ in women. The estimated population for the district

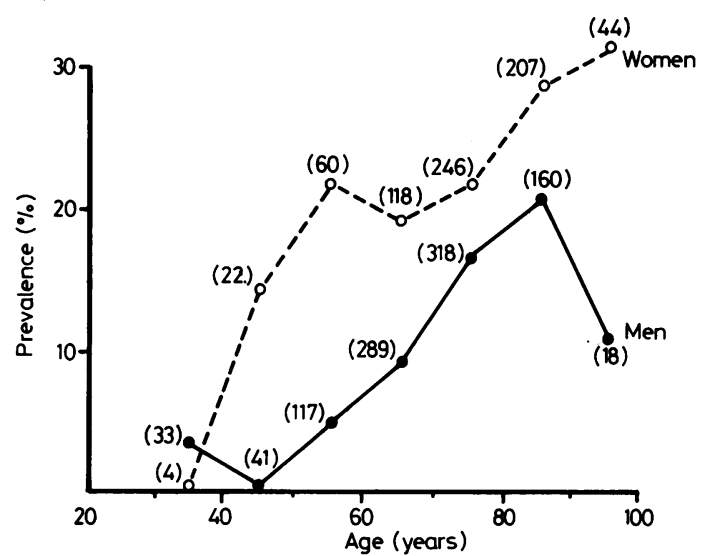

Figure 1 Prevalence of gall stones at necropsy by decade. Number of subjects in parentheses. (In the decade 20-29 none had gall stones - M16:F8).

over this period was 249000 (Source OPCS: projected from 1971 Census).

\section{GALL STONE RELATED DEATHS}

There were 21 gall stone related deaths among the 8078 cases studied $(0.26 \%)$ but in the 291 subjects with known gall stone disease the rate was $3.4 \%$.

There were 424 cholecystectomies carried out in the district during this period and there were five postoperative deaths (mortality rate $1 \cdot 2 \%$ ).

The first two postoperative deaths listed in Table 1 were not related to operative technique, but in the other three there were complications which were perhaps avoidable. There were six gall stone related deaths in the necropsy group which were not postoperative and all but one were in the eighth or ninth decade. Carcinoma of the gall bladder was found in one woman aged 90 years who had gall stones. Ten further deaths were identified in the "no necropsy group' in which the death certificate suggested a gall stone related death and all but one were over the age of 70 years.

\section{CHOLECYSTECTOMY RATE}

The annual cholecystectomy rate over the 29 month period was $175(70 / 100000$ population per annum) and $73 \%$ were carried out in women. The number of cholecystectomies per head of the population at risk rose with age in both sexes (Fig. 2) but fell off sharply in the seventh decade in women and the eighth decade in men. Only $6 \cdot 8 \%$ of all operations were carried out in patients over the age of 75 (12 men and 17 women). It is estimated that there are 13000 women and 6000 men over the age of 75 in south-east Kent (source: OPCS). 
Table 1 Gall stone related deaths

\begin{tabular}{|c|c|c|c|c|c|c|c|c|}
\hline \multirow[b]{2}{*}{ Postcholecystectomy } & \multicolumn{4}{|c|}{ Necropsy group (1701) } & \multicolumn{4}{|c|}{ No necropsy group (6356) } \\
\hline & Sex & Age & & No & $\operatorname{Sex}$ & Age & & No \\
\hline \multirow[t]{4}{*}{ Mean age 60} & $\mathbf{M}$ & 50 & \multirow{2}{*}{$\begin{array}{l}\text { gall stone pancreatitis jaundice. } \\
\text { Retained stone postexplorn.CBD. } \\
\text { CVA. Jaundice. postop site } \\
\text { satisfactory. explorn.CBD. }\end{array}$} & 1 & \multirow[t]{4}{*}{$\mathbf{M}$} & \multirow[t]{4}{*}{67} & \multirow[t]{4}{*}{$\begin{array}{l}\text { leaked bile }++ \text { post- } \\
\text { operation. }\end{array}$} & \multirow[t]{4}{*}{1} \\
\hline & $\mathbf{F}$ & 60 & & 1 & & & & \\
\hline & $\mathbf{F}$ & 72 & $\begin{array}{l}\text { Morbid obesity. Recurrent } \\
\text { pancreatitis. Duodenal fistula. } \\
\text { explorn.CBD. - ve }\end{array}$ & 1 & & & & \\
\hline & $\mathbf{F}$ & 49 & Re-explored for bleeding. & $\begin{array}{l}1 \\
4\end{array}$ & & & & \\
\hline No Operation & $\mathbf{F}$ & $80 \& 92$ & Cholangitis & 2 & \multirow{4}{*}{$\begin{array}{l}\mathrm{F} \\
\mathrm{M}+\mathrm{F} \\
\mathrm{F}\end{array}$} & \multirow{4}{*}{$\begin{array}{l}80 \\
\text { all }>70 \\
\text { all } \geqslant 65\end{array}$} & \multirow{4}{*}{$\begin{array}{l}\text { Cholangitis } \\
\text { pancreatitis } \\
\text { acute cholecystitis }\end{array}$} & 1 \\
\hline \multirow[t]{3}{*}{ Mean age $81(65-93)$} & $\mathbf{F}$ & $70 \& 86$ & Gall stone pancreatitis & 2 & & & & 4 \\
\hline & $\mathbf{M}$ & 82 & Gall stone ileus & 1 & & & & 5 \\
\hline & $\mathbf{M}$ & 91 & Empyema gall bladder liver abscess & 1 & & & & 10 \\
\hline
\end{tabular}

\section{CHOLECYSTECTOMY RATE IN LUTON}

The number of cholecystectomies per head of population carried out in Luton in 1981 had again risen when compared with 1961 and $1971^{7}$ (Table 2). The difference between 1971 and 1981, however, failed to reach statistical significance.

\section{Discussion}

This study shows that the prevalence of gall stones in the adult population was $17 \cdot 1 \%$ and yet only $10.7 \%$

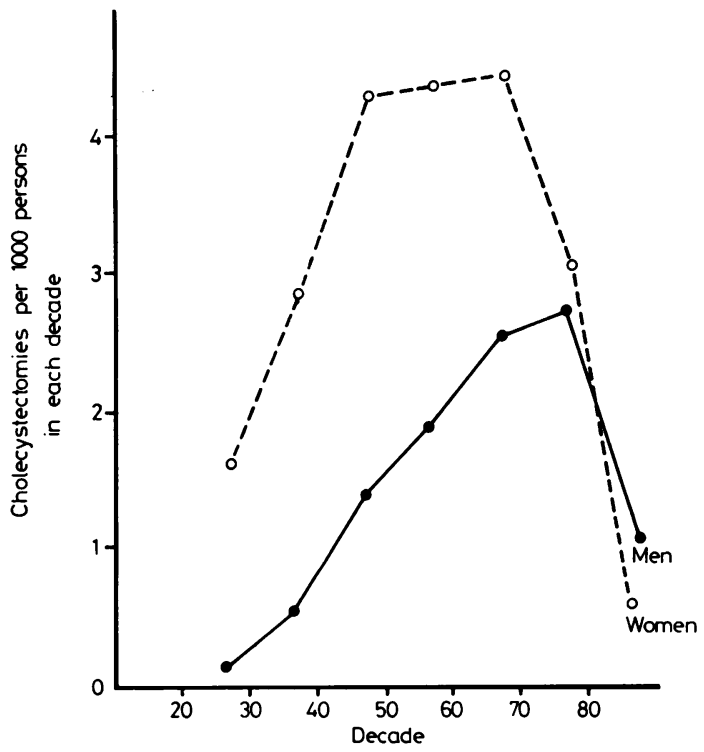

Figure 2 Number of cholecystectomies per 1000 population at risk, for each decade (over $2 \frac{1}{2}$ years). of these had been removed in life. In a study of nine British towns Barker and his colleagues ${ }^{12}$ found a similar necropsy cholecystectomy rate of $11.4 \%$ and, while this kind of series is not a true sample of the population, it is probable that nine out of 10 people with gall stones in Britain never have had a cholecystectomy.

If a silent stone is found incidentally, many suggest that it should be removed to avoid future complications. $^{1-3}$ It can be argued that the logical progression of this policy would be to screen the population at risk and carry out a cholecystectomy in those shown to have gall stones. Quite apart from the practical consequences of adopting such a policy it would be essential to show that the mortality rate of elective cholecystectomy gives rise to significantly fewer deaths than the natural history of unoperated gall stones.

The increasing cholecystectomy rate at Luton fails to reach significance for the latest period, 1971-1981 but there is overwhelming evidence that the number of cholecystectomies per head of population in this country is rising. ${ }^{6-10}$ There have been several suggestions that this noted increase in cholecy-

Table 2 Annual cholecystectomy rates for Luton (Bedfordshire)

\begin{tabular}{|c|c|c|c|}
\hline Year & Population & Operations (no.) & \% of population \\
\hline $1961^{*}$ & 204000 & 72 & $0.034 \%\} n<0.001$ \\
\hline $1971^{*}$ & 250000 & 166 & $0.066 \%$ \\
\hline 1981 & $271200+$ & 213 & $0.079 \%$ \\
\hline
\end{tabular}

* Data from Plant, Percy, Bates et al (1973). ${ }^{7}$

† Source 1981 census OPCS (preliminary figure).

$\ddagger$ Test for equality of proportions. 
stectomy rate may be the result of the availability of surgical resources rather than a true increase in the prevalence of gall stones. ${ }^{8-10} 13$ It seems likely that the prevalence of gall stones in this country is gradually increasing. Brett and Barker ${ }^{13}$ found in a review of the literature that the necropsy prevalence in Europe pre-1940 was $10.5 \%$ and the average figure post-1940 is $18.5 \%$. Canada, however, has a cholecystectomy rate ${ }^{713}$ which is five times higher than in England and Wales but there is no evidence that there is a corresponding difference in the prevalence of gall stones to account for this ${ }^{14}$ nor does it seem likely that the prevalence of gall stones in Luton doubled in the 10 years from 1961 as the cholecystectomy rate did. ${ }^{7}$ Vayda $^{13}$ has shown that gall stone related mortality is twice as high in Canada as it is in this country and he suggests that some of the excess mortality may be the result of increased surgery. The cholecystectomy rate was $70 / 100000$ population in this district and as there was no waiting list for cholecystectomy during this period, it seems unlikely that more than a handful of patients left the district for operative treatment elsewhere. The rate in Luton was 79/100 000 (1981) and in Bristol 76/100 $000(1970),{ }^{6}$ but these rates contrast strongly with that of $240 / 100000$ in Windsor, Ontario (1971). ${ }^{7}$

The necropsy cholecystectomy rate in Oslo in the 1950 's was $7 \cdot 1 \%^{15}$ but the proportion of gall stone related deaths in those with gall stones was the same as in the present study $(3.4 \%)$. This is half the mortality rate found in Dundee ${ }^{11}$ but the numbers are small and the difference is probably not significant.

The operative mortality in the present series was $1.2 \%$ and this falls within the expected range. ${ }^{5}$ One cannot tell how many patients would have died if they had not been operated on but on the other hand, all but one of the gall stone related deaths under the age of 70 were postoperative. The few deaths that did occur from unoperated gah stones were nearly all in the very elderly and the district studied has a high proportion of elderly people in the population. On reviewing the five postoperative deaths in this series, the indications for surgery were symptomatic gall stones in each case. Two patients under the age of 70 with uncomplicated gall stones, however, died after elective cholecystectomy.

The small number of cholecystectomies carried out in the elderly is in contrast to the rising prevalence of gall stones (Figs. 1 and 2). While the total number of subjects at risk is smaller in the older age group, the main factor seems to be an increasing reluctance on the part of the surgeon and the patient to undertake a major operation for benign disease.
A further argument advanced in favour of cholecystectomy for silent stones is the possibility of a subsequent carcinoma of the gall bladder. There is a reported prevalence of $1-30 \%$ gall bladder carcinoma in the presence of stones ${ }^{15}$ but Torvik and Hoivik found only $2 \%$ with carcinoma, and pointed out that they were nearly all elderly women with a short history of symptoms. In the present study only one carcinoma of the gall bladder was found in a woman of 90 out of a total of 291 subjects with gall stones. The mortality of elective surgery for gall stones allows little potential benefit from cholecystectomy to avoid future malignancy.

As expected, gall stones were twice as common in women as in men and the prevalence rose steadily with age in both sexes. Of those subjects with gall stones, however, women were three times more likely to have had a cholecystectomy than men and it seems possible that they are more likely to have upper abdominal dyspepsia investigated by a cholecystogram leading to the discovery of gall stones and an operation.

The main limitation of the present method of studying gall stone related deaths is the low necropsy rate $(21 \%)$. Sudden death outside the home is more likely to lead to a coroner's inquiry and the noted preponderance of men in such studies may be explained in part by their higher incidence of coronary heart disease. It has been suggested that there may be an inverse relationship between coronary heart disease and gall stones ${ }^{12}$ and it is possible that this may lead to an underestimate of the latter condition in a necropsy series. Even with the highest necropsy rate found in Barker's study ${ }^{12}$ $(40 \%)$, the same criticism applies and it is difficult to see a better way of estimating gall stone related deaths given that all death certificates issued over the same period were examined and recorded. Furthermore, both the necropsy and the death certificate studies were prospective so that close liaison was maintained with all the district pathologists and the office of the district medical officer throughout the study.

Most surgeons would deny that gall stones are removed as a reflex action ${ }^{16}$ but with an increasing number of surgeons ${ }^{17}$ and a gradual improvement in surgical resources, a further rise in the cholecystectomy rate can be expected in this country. ${ }^{891819}$ The economic consequences of a more aggressive surgical policy would be considerable and some potential benefit should be shown before such a change evolves.

The operative mortality of elective cholecystectomy is very low but if the incidence of cholecystectomy continues to rise it seems likely that more people will die of postoperative complications 
than would have been saved from potentially fatal complications of their gall stones. ${ }^{5}$ At least in terms of mortality, there does not appear to be any potential benefit from further increasing the present level of surgery for gall stones.

We thank Professor $M$ Warren for advice in undertaking this study. We thank Mr J A Girling, Mr D Keown, Mr J McPartlin, Mr C Derry and Mr $\mathrm{N} J$ Griffiths of the SE Kent Health District and $\mathrm{Mr}$ R V Fiddian, Mr M W Mee, and Mr R RothwellJackson of the Luton and Dunstable Hospital for permission to study records of patients under their care. We would also like to thank Drs S MacKenzie and $T$ Trace for their help in tracing the death certificates, D G Wells for carrying out many of the necropsies and $P$ Wheeler for help with the manuscript. We also thank Mrs J Slater and Miss M Emmerson.

Mrs M Harrison and Mr T Bates are in receipt of a grant from the SE Thames Region Locally Organised Research Scheme. The statistical analyis was carried out by Dr P M North and Mr N Maine.

\section{References}

1 Glenn F. Silent gallstones. Ann Surg 1981; 193: 251-2.

2 Wenckert A, Robertson B. The natural course of gallstone disease. Eleven year review of 781 unoperated cases. Gastroenterology 1966; 50: 376-81.

3 Comfort MW, Gray HK, Wilson JM. The silent gallstone: a ten to twenty year follow-up study of 112 cases. Ann Surg 1948; 128: 931-7.

4 Gracie WA, Ransohoff DF. The natural history of silent gallstones. The innocent gallstone is not a myth. $N$ Engl J Med 1982; 307: 798-800.

5 Hoey J, Psihramis K. Cholelithiasis: a comparison of surgical and non-surgical management strategies based on available evidence. Clin Invest Med 1979; 2: 75-81.

6 Holland C, Heaton KW. Increasing frequency of gallbladder operations in the Bristol clinical area. $\mathrm{Br}$ Med J 1972; 3: 672-5.

7 Plant JCD, Percy I, Bates T, Gastard J, de Nercy YH. Incidence of gall-bladder disease in Canada, England and France. Lancet 1973; 2: 249-51.

8 Fowkes FGR. Cholecystectomy and Surgical Resources in Scotland. Hlth Bull (Edinb) 1980; 38: 126-32.

9 Quill DS, Devlin HB, Plant JA, Denham KR, McNay RA, Morris D. Surgical operation rates: a 12 year experience in Stockton on Tees. Ann R Coll Surg 1983; 65: 248-253.

10 Gunn AA. The management of gallstones. In: Recent advances in surgery. Edinburgh: Churchill Livingstone, 1982: 183-96.

11 Bateson MC, Bouchier IAD. Prevalence of gallstones in Dundee: a necropsy study. Br Med J 1975; 4: 427-30.

12 Barker DJP, Gardner MJ, Power C, Hutt MSR. Prevalence of gallstones at necropsy in nine British towns: a collaborative study. $B r$ Med J 1979; 2: 1389-92.

13 Vayda E. Comparison of surgical rates in Canada and - in England and Wales. $N$ Engl J Med 1973; 289: 1224-9.

14 Brett M, Barker DJP. The world distribution of gallstones. Int J Epidemiol 1976; 5: 335-41.

15 Torvik A, Hoivik B. Gallstones in an autopsy series. Incidence, complications and correlations with carcinoma of the gallbladder. Acta Chir Scand 1960; 120: $168-74$.

16 Anonymous. Stones without fire. [Editorial] Lancet 1980; 1: 403-4.

17 Short Report. Fourth Report from the Social Services Committee. London: HMSO 1982.

18 Bunker JP. Surgical Manpower. A comparison of operations and surgeons in the United States and in England and Wales. $N$ Engl J Med 1970; 282: 135-44.

19 Wennberg J, Gittelsohn A. Small area variations in health care delivery. Science 1973; 182: 1102-8. 